\title{
Memória, palavras, murmúrios e silêncios: Óssip Mandelstam
}

\author{
Jerusa Pires Ferreira
}

Já havia resenhado livros de Mandelstam em português e tentava então, nos seminários que ofereci em Limoges, passar para o francês muitas das referências e ampliar o universo de conhecimento da poesia e das vivências do grande poeta.

Entro numa livraria em espaço tão importante das letras francesas e da paisagem cultural em torno da velha Sorbonne e adjacências, em Paris, para procurar obras de Óssip Mandelstam e escritos sobre ele traduzidos em francês. De repente, numa seqüência de estante, recupero capas, títulos e, mais que isso, tenho de fazer opções, conforme as soluções poéticas. Do Rumor do Tempo, Viagem à Armênia e ao Selo Egípcio, há diferentes traduções. Resolvo ficar com Le Bruit du temps, Voyage en Arménie e Le Sceau égyptien. E também com a forte evocação de sua presença, justamente naquele lugar onde viveu momentos tão importantes de sua juventude, e a comoção diante de uma das mais trágicas vidas, e uma das indiscutíveis e mais reconhecidas vozes poéticas do século XX.

Sabe-se que nasceu em Varsóvia, Polônia, no ano de 1891 e isto já constitui uma verdadeira questão.

\footnotetext{
"Nasci no ano de noventa e quatro,

Nasci no ano de noventa e dois ...

No punho guardo o ano gasto ,

No punho, homens, feras, laço

E então entoam-me os lábios fracos:

Nasci na noite de janeiro, dois

Pra três,no ano de noventa e um,

No ano da desdita e do malogro

E os séculos me cercam como fogo". ${ }^{1}$
}

É como se tivesse vindo ao mundo num intervalo, numa divisão, como se a partir deste momento, tivesse algo de estranho a carregar, a marca de Caim. Proveniente de uma família judia originária da Lituânia, pouco tempo depois de seu nascimento, seus pais se instalaram em São Petersburgo, onde seu pai era comerciante de peles e sua mãe, que tinha sonoro e sugestivo nome - Flora, professora de música. Esta confusão de datas se deve também à diferença de calendários. Consta que entre os calendários Juliano, usado então na Rússia, e o Gregoriano, no ocidente, havia 13 dias de distância.

Assim também, e por outros motivos, sua morte é cercada de mistério e ficou por muito tempo em discussão a data em que o poeta deixou de existir, premido pelas duras condições a que esteve sujeito, das prisões aos campos de trabalho. Saúde frágil, sua sensibilidade extraordinária não poderia resistir, e há um documento que nos deixa ainda hoje tão perturbados: é quando contemplamos sua foto com roupas de detento. O retrato do artista quando preso, de frente e de perfil. 
Detido em Moscou em 1934, passaria pelo tormento de deslocações forçadas pela Sibéria Oriental, e antes de aí chegar para viver, tenta suicídio. Uma outra residência lhe é imposta, Voronej, onde ele e sua mulher Nadiéja vivem por cerca de 3 anos, até abril de 1937. Experimentaram dificuldades indescritíveis. A proibição de exercer atividades remuneradas traria fome e grande necessidade de aquecimento e de abrigo. Mesmo assim, aí ainda compôs um livro de intensa realização poética, que se chamou Cadernos de Voronej.

Preso em maio de 1938, viria a morrer alguns meses mais tarde num campo de triagem, para onde os deportados eram mandados, a caminho de Kolyma, sinistra referência. Continuam a ser, de fato, um mistério a data e a causa/ mortis.

Ao rever materiais em Os Escombros e o mito (1997), Boris Schnaiderman se refere ao grande poeta apontando que ele sofria de crises nervosas e que, mesmo sem desenvolver atividade política, foi retirado de sua casa em 1934. Teria precipitado sua prisão o famoso poema a Stalin, em que este aparece com bigodes de barata (Mandelstam, 2001b: 212). Diz-nos também que na era soviética o poeta era editado muito parcialmente, e que só a partir da década de 60 seus textos começam a circular.

Recuperando tempos amenos, diremos que, tendo ido viver muito jovem em Paris, alojado na rue de Sorbonne número 12, onde freqüentava também as reuniões de emigrados, Mandelsatm assistia de maneira muito irregular, no Collège de France, os cursos de Henri Bergson e o de Joseph Bédier, o grande medievalista, estudioso da epopéia francesa, presenças estas que lhe deixaram forte marca. Assim, iria se iniciar também na poesia francesa desde a Chanson de Roland aos textos de François Villon, de Paul Verlaine e Mallarmé, sendo que Verlaine foi de fato uma espécie de presença tutelar, como se pode acompanhar nos poemas de (La) Pierre (1906-15), Pedra ou Kamien.

Passa breves temporadas na Suíça e na Itália do Norte, faz estudos em Paris, e durante um semestre na Universidade de Heidelberg. Em 1908, volta a São Petersburgo, pensa em seguir seus estudos na Universidade da Capital Imperial, mas diante de uma cota restrita imposta a postulantes judeus, teria desistido. Passa então a freqüentar a Sociedade de Filosofia Religiosa e depois a Academia. A partir de 1909, experimenta uma fase de intensa criação, sendo estes os anos mais fecundos de seu fazer, sobretudo de 1918 a 1922 , ao lado do que seria e, de outra maneira, a fase em que produziu os Cadernos de Voronej que se diz o seu canto de cisne em 1937(Mandelstam, 2003).

Sempre estimulado pela mãe, sabemos que passou a freqüentar o salão literário do grande poeta simbolista V. Ivánov e começa então a publicar poemas nas revistas Apolo e Hiperbóreo, então de grande prestígio.

Fala-se em uma conversão em 1914 à religião cristã. A conversão também visaria, de certo modo, sua admissão na Universidade russa.

Poemas do período de Pedra, seu primeiro livro, e de Tristia (Coisas tristes), mostram uma elaboração religiosa, apesar do paganismo e da presença intencional do mundo greco-latino. Em um longo ensaio sobre Mandelstam, Henri Abril nos fala de uma poética associativa e intertextual, referindo-se a ele como um acmeísta "avant la lettre". O livro Tristia, que aparece em Berlim em 1922, e em São Petersburgo no ano seguinte, é um título emprestado a Ovídio, e é uma viagem à terra e à cultura de Homero, Ovídio, Catulo. Somos levados a acompanhar este percurso em nossa língua, na bela tradução de Augusto de Campos, com a participação de Boris Schnaiderman: 
"Insônia. Homero.Velas rijas. Naves:

Contei a longa fila até metade.

Barcos em bando, revoada de aves

Que se elevou outrora sobre a Hélade.

Uma cunha de grous cortando os céus -

Sobre a fronte dos reis cai a espuma divina -

Para onde seguis? Não fosse por Helena,

O que seria Tróia para vós, Aqueus?

O mar e Homero - a tudo move o amor.

A quem ouvir? Mas Homero está quieto

E o mar escuro, declamando, com clamor,

Ruge e estertora à beira de meu leito.....” (Mandelstam, 2001b: 209)

Não poderemos, portanto, deixar de apontar a convergência de muitos pensamentos, posicionamentos e culturas na obra deste poeta singularíssimo. Convivem o pensamento judaico e o greco-cristão, por exemplo, o conflito permanente entre as opções e as imposições do meio, a construção de uma literatura que seguiria tendências, momentos, processos, trazendo a força de uma individualidade poética das mais demarcadas.

É preciso no entanto levar em conta que das injunções literárias às da vida pessoal, em seus impasses, foram se criando abismos, cobrando-se decisões impossíveis, desde a sua crítica à burguesia e sua adesão aos primeiros momentos revolucionários, bem como a dificuldade de conviver com o endurecimento do regime soviético.

Sua confissão corajosa em várias passagens e no belo livro de Memórias (ou de anti-memórias) que é Rumor do Tempo não significaria uma rejeição à sua "identidade forte" mas, a meu ver, constatação de como lhe era difícil compatibilizar vida e história.

O discurso poético apreende aí muito mais do que se poderia fazer de outro modo, e nos oferece sobre a noção de identidade cultural, páginas extraordinárias, que trazem do pessoal ao social, em ondas contínuas. Cabe muito bem a intensidade da noção de crise, na busca de compatibilização das várias correntes identitárias (Pires Ferreira, 2004: 39).

Há quem o censure, por exemplo, pela forma com que ali evoca o pai e seu universo, quem condene a inflexão de ironia que aí se tece, ao confrontar mundos que se antagonizam, ao falar, por exemplo, do caos judaico, ao dizer que na cabeceira se defrontavam a Bíblia e o militarismo russo.

Mas é preciso avaliar em profundidade as entrelinhas destas relações e seguir a admiração que ele nutria pela cultura autodidata do pai Emil, além de acompanhar todo um afeto que está presente em suas cartas a ele, a íntima relação, o conselho e apoio buscados, sua inserção no judaísmo.

No poema Sol Negro, traduzido por Nelson Ascher e Boris Schnaiderman referindo-se à morte de sua mãe, diz-nos o poeta:

\footnotetext{
"Mais atroz é o amarelo e no templo iluminado, nana, neném minha mãe por judeus era velada.
} 
A voz dos hebreus tinia

Sobre minha mãe e, imerso

No fulgor do negro sol,

Eu despertei no meu berço” (Slavutzky, 1998: 89-90)

Mas tudo isto é um amplo universo de memória, cheio de tantas sutilezas a desvendar! Diz- nos Jean Blot, organizador de volume da coleção Poetas de nosso tempo, para a editora Seghers, que oferecer uma síntese das idéias de Mandelstam não é uma tarefa que possa nos parecer fácil.

$\mathrm{Na}$ idade de 16 anos, o jovem descobre a poesia simbolista francesa de Verlaine, mas estuda também o francês antigo e mergulha no mundo medieval, de onde ressai a presença de François Villon. Esta aproximação já foi comentada, quando se considerou que aquilo apontado por Mandelstam em Villon, se pode dizer dele mesmo, ou seja, que tem a arte de isolar instantes, processá-los em memória, guardando um incomparável frescor.

Depois, na Rússia experimentaria o entusiasmo de se ligar a poetas, construindo uma plataforma do acmeísmo, movimento artístico que traria uma posição especial para a fusão do modernismo e das vanguardas com o classicismo, em companhia de Gumiliov e de Ana Akhmátova, forte presença.

Esta imersão no mundo clássico, que, em certa medida, representa uma reação aos simbolismos de então, constitui aquilo que o leva a declarar que a língua russa é helenística. Dedica-se então a entender esta compatibilidade e assim nos fala num poema de 1918:

"Toma para tua alegria, de minhas palmas

Um pouco de sol e um pouco de mel

Como nos ditaram as abelhas de Perséphone"

Assim, o poeta vai proceder a uma imersão na análise da natureza da linguagem ou em suas relações com o mundo. Daí o seu entusiasmo, que nos é transmitido pela História Natural e pela natureza biológica, oferecendo toda uma matriz de pensamento para o texto literário, construindo estreitas ligações entre as teorias da natureza e da cultura. Deste modo, o seu poema sobre Lamarck e pequenos textos de Viagem à Armênia - um poderoso livro de viagem e de memórias.

Discute naquele livro o que considera o conteúdo vital dos armênios e sua prática de guiar-se pelos relógios de sol, como o das ruínas de Zvardnódze, em forma de roda astronômica ou rosa gravada em pedra. E começa a detectar nesse povo, desde aquilo que julga ser a ausência de metafísica até a vocação filológica, imergindo em considerações sobre a língua armênia, suas formas de pronunciar, suas etimologias. Assim é a Armênia, ele nos diz, e vai apontando. A cor o prende, o olhar se reativa como função principal, e é então que aproveita para discutir tudo o que vê. Mas é preciso não esquecer que esta viagem que é, todo o tempo, distensão e descoberta e que nos é oferecida em imagens fotográficas de então estava carregada de episódios dramáticos. Talvez tenha sido esta a 
sua última e possível escapada, pois sabemos que o retorno do poeta e de sua mulher, naquela ocasião, foi quase forçado.

Na notável aproximação entre Natureza e Cultura, ele nos oferece preciosos comentários que vão dos besouros ao ardor das papoulas, dos alfabetos do Cáucaso. Aliás, pude pessoalmente conferir, experimentando um encantamento especial, no que toca à concepção e desenho dos alfabetos.

O poeta usa a possibilidade desse espaço para discutir ciência, pintura, literatura, em geral. Apaixonado pelo naturalismo, não deixando faltar a referência a Goethe e ao Fausto, e tendo em Lamarck um avatar (único naturalista shakespereano, como afirma), não hesita em opô-lo a Darwin, em seu evolucionismo, para ele indesejável.

Nesta incursão e propiciando trocas entre a natureza e todo um processo de explicála ou de representá-la, em que as coisas sofrem uma espécie de animização, e em que lemos: "a ilha ficou enjoada como mulher grávida", Mandelstam nos leva então a abrir novas frentes para pensar sobre o tema e oferece um canal de memória que é, não a recordação e a relembrança amenas, mas a força da memória com todos os seus parasitas.

Transparecem aí suas contradições e o pacifismo do poeta, pois em ode composta em 1916, inspirado pelo medo, desenvolve em estilo épico e guerreiro. A Ode de ardósia, em sua complexidade (Struve, 1982), evoca as novas condições para o exercício da criação poética. Passa a usar porém, a partir de um certo momento um tipo de cripto-linguagem e mensagens do silêncio, sendo que num verso ele conclui:

"Correrá chumbo sobre teus lábios" (Struve, 1982, trad. do francês por Jerusa Pires Ferreira)

No poema "Leningrado", também bastante conhecido, a cidade-mito, a velha São Petersburgo, verdadeira personagem de Rumor do tempo, evocada na plenitude da memória em suas cores, hábitos, odores, cria-se uma espécie de prosopopéia, um diálogo com a cidade fantasma que, em certo momento, merecera do poeta o comentário seguinte: viver em Petersburgo era como dormir num túmulo.

E em momento de revisita declara, em sua presentificação do tempo vivido, apontando para os mortos:

\footnotetext{
"Petersburgo! Não quero morrer ainda , Sei que tens meus números em tua agenda .

Petersburgo! Também preservo as notas

Com os números de toda a gente morta" (idem)
}

Mas antes disso já dissera:

"A erva, nas ruas de Petersburgo, é apenas os primeiros passos da floresta virgem que viria recobrir o próprio lugar das cidades modernas. Toda esta jovem verdura viva e tenra, espantosa de frescor, pertence a uma nova natureza espiritualizada. Em verdade. Petersburgo é a mais vanguardista das cidades do mundo. Porque não são os arranha-céus nem o metrô que vão dar a medida do destino do mundo moderno: a rapidez - mas a feliz ervinha em vias de abrir caminho por entre as pedras da cidade" (Mandelstam, 1990b).

Quanto ao poema "Odeio a Luz", temos aí a síntese do processo criador de Mandelstam, que se revela de modo admirável em Rumor do Tempo. A recusa à memória, 
descartando, quando de fato se está pedindo e fazendo memória, o rejeito do que incomoda, mas que se insurge e se insere na construção inevitável de seu texto, que aciona o ódio ao que se busca. Comentou-se que ele parece recusar a afirmação, aspirando voltar em direção à natureza e ao reino das sombras.

O poema "Odeio a luz" é o exemplo do tormento que paira sobre o exílio e o degredo vivido na própria pátria. O canto de quem não partiu, e que nas trilhas de Ana Akhmatova declara:

\footnotetext{
"Sou meu caminho e degredo

Quando estes acabarem, volto

Lá não poderia amar,

Aqui, de amor, eu tenho medo"
}

Temos sempre em Mandelstam um potente trabalho da memória, um texto impregnado daquilo que experimentou um poeta-memorialista em seu ofício de evocar, destruir e recompor. Como Proust (e eles são contemporâneos), o autor vai sondar a grande complexidade das relações de tempo/espaço, do tempo psicológico, em seus vários momentos e matizes, entramados no desenrolar do tempo social.

O autor se faz intérprete de muitas avaliações e sondagens de situações vividas; depreende marcas identitárias e as sujeita à experiência pessoal por onde passa o social, colocando ênfase no desconforto.

Mas Rumor do Tempo causaria, desde o seu aparecimento em 1925, uma polêmica, e questionado sobre este livro, respondendo por longa parte de sua poesia, ele procura mostrar que o olho é o instrumento do pensamento, que a luz é uma força, e o pensamento todo um trabalho.

Procurei acompanhar passagens como estas no meu estudo sobre os livros em prosa do poeta, em que o tempo é um vigoroso protagonista, e em que se processa um percurso muito semantizado pela cultura, em suas muitas instâncias, do pessoal aos organismos sociais. Vão se revelando fatos, práticas, acertos e contradições.

Não poderemos continuar a tratar deste tema e ingressar no domínio do poético, sem recorrer a muitos estudos sobre o tempo na obra de Mandelstam, e nos diz Joseph Brodsky, num inteligente e polêmico ensaio sobre o poeta, publicado como prefácio da tradução espanhola de Tristia (Mandelstam, 1998), que o tempo na obra de Mandelstam tem o seu lugar dentro do poema, e é uma cesura.

Desde o início, o que faz parte da obra do jovem poeta, prolongando-se, é a idéia de um tempo sobrecarregado: "servindo-se, sem cessar, de todo o poder fonético e alusivo das palavras".

Daí a recomendação de Brodsky para que se leia esta obra em russo; a poesia de Mandelstam se expressa na dilatação, na sensação viscosa da passagem do tempo. Ele nos diz que aí o leitor se dá conta de que as palavras, inclusive as letras e de maneira especial as vogais são quase palpáveis vasilhas do tempo. Discorre, criando aproximações e diferenças com Proust, e também analisa o sistema de versificação russa, apontando como ao tratar do tempo, o poeta recorre a um verso fortemente cesurado, que tem ressonâncias do hexâmetro, tanto em ritmo como em conteúdo. 
Apesar da perda que experimentamos, ao ler em traduções para outros idiomas, não podemos deixar de constatar a sensibilidade de vários tradutores que nos fizeram possível o acesso em outras línguas, encontrando nelas a boa recriação e que se abre sobre outros sistemas expressivos.

No que toca à oralidade, diz-se que nesta Odisséia do poeta (Mandelstam, 1990b), ele inventa a forma moderna de uma poesia épica. Que a poesia de Óssip Mandelstam é um retorno à oralidade, e lhe é atribuída a seguinte frase:

\footnotetext{
"Sou o único na Rússia a compor de viva voz":

"Du moins ils ne purent m'ôter

Le remuement de mes lèvres"
}

Pelo menos não me podem tirar o movimento dos lábios, dirá ele, pouco antes de morrer, e esta imagem tão forte nos prenuncia sua imperecibilidade. É este movimento do sopro e da voz que nos instiga a prosseguir.

Mas os seus ensaios nos revelam tanto de sua arte poética quanto dele próprio. Óssip Mandelstam não é apenas um grande poeta da literatura mundial pela riqueza de seu pensamento e escrita, a que se acrescenta muito humor, mas à sua maneira, aquele que realiza a confluência de culturas diversas sujeitas ao filtro de uma percepção singular.

No pungente e belo volume de sua correspondência (Mandelstam, 2000a), faz-se sua apresentação mais uma vez, como sendo um dos maiores poetas do século XX, e em que a palavra foi fixada por escrito freqüentemente pelos outros. Ela pôde subsistir por sua colocação em cadernos escolares, nos quais sua mulher Nadiédja transcrevia as estrofes que ele lhe ditava. Um escritor para além da escritura, inscrito de vários modos e também, oralmente, na cultura universal.

O que me fascina, para além da grandeza poética de Óssip Mandelstam, é a fisicalidade de seu texto e o seu operoso e contundente trabalho com a Memória, a força pela qual a nega enquanto a constrói. O fato de dizer seus poemas, e colocá-los no movimento dos lábios, na dicção e no insistente sopro de vida.

Passamos a saber que a elaboração do material sonoro e rítmico de seu verso e sua prosa bem como o de suas traduções se fazia verbalmente (Mandelstam, 2000a). Ele murmurava, andando através do quarto e depois, se punha a ditar.

Uma poesia em que a memória é mais que matéria - é suporte pleno, fluxo corporal. Momento de corporeidade em que o passado se ativa e projeta de viva voz. Sabemos também que esta regra de não-recurso à escritura que ele mesmo proclamava, admite uma exceção: sua correspondência, aos amigos, à mulher, a diversas personagens e instâncias do mundo literário. De fato, contamos com o fato de ele ter escrito cartas admiráveis, em que respira na plenitude de sua relação com o mundo e os outros seres, toda sua fé na dignidade e liberdade do homem.

E, como se costuma dizer, é um milagre que estas cartas tenham sido conservadas, nas condições extremamente difíceis da era stalinista, e resistido à guerra. Sua cunhada, por exemplo, por medo, queimou todas aquelas que dirigiu a seu irmão Aleksandr.

Em 1997 as edições Art-business - Tsenter, de Moscou, publicaram, pela primeira vez o conjunto das cartas de Mandelstam de que dispomos, ou seja, 247 cartas escritas ou 
ditadas pelo poeta, de 1903 a 1938. A última foi escrita em 1936, no campo de trânsito de Vladivostok, um mês e meio antes de sua morte.

Sobre o fim trágico que teve, destaca-se o papel extraordinário das Memórias de Nadjiéja Mandelstam, primeiramente editadas em russo no ocidente.

Suas cartas e as revelações de sua mulher, que cultivou e exerceu as artes da memória como um instrumento ativo contra o esquecimento forçado, representam mais do que importante material, para se seguir os passos de uma história pessoal, política e cultural de seu tempo, dos caminhos da poesia e da dolorosa, intensa e criativa relação deste escritor com o mundo e com as artes, tanto em suas tradições como nas operações renovadoras.

Entre as várias versões sobre o que lhe teria acontecido, há a de que teria morrido exaurido num campo de trabalho na Sibéria, mas como já antevira em seu poema, seus lábios se fariam ouvir, a partir de Varonej, onde a inspiração lhe viera cada vez mais pródiga. No ano de 1972, ele seria revelado aos leitores franceses, através das lembranças de sua mulher e pelas traduções que não haveriam de parar no Ocidente.

Nikita Struve (1982), que traduziu Rumor do Tempo e escreveu Óssip Mandelstam, um alentado volume sobre o poeta, compara a sua obra a uma verdadeira chuva de grãos.

No que concerne a Mandelstam, foi um dos primeiros, em determinado momento, a fazer da palavra verbalmente expressa, a unidade inesgotável autônoma e suficiente do ato poético, a base de uma nova arquitetura verbal. Aponta-se em sua obra o peso visual da palavra verbal e vice-versa, e há toda uma importante viagem a se fazer através de seus escritos sobre a poesia, o tempo, a memória, a natureza, seus materiais prediletos, quase um destino.

No começo, não era possível prever que Mandelstam se tornaria o poeta do tempo em todas as suas dimensões, e ainda mais o poeta pleno de seu tempo. Num dos tópicos de que trata, nos convida num belo título a avançar ao entendimento de Mandelstam: Nos Confins do Silêncio.

Quanto à sua figura tão presente, conta-se que não era belo, mas cheio de um encantamento próprio, e por descrição de mais de uma pessoa, aprendemos que se assemelhava a um pássaro. Evocando seus apelidos e seus gestos, encontramos que "o judeuzinho jubiloso era também tão majestoso como uma fuga", gênero musical (Mandelstam, 2003). Passamos também a saber que na ocasião da segunda edição de seu primeiro livro, Mandelstam já estava pronto para afrontar seu destino e sua história.

Quanto ao seu texto ele continua a se recriar em várias línguas, em livros, em traduções, em coletâneas de ensaios e na repercussão da incrível memória de sua companheira que se transformou num notável arquivo de criação, de poesia e de desespero diante do inexorável.

Notas

${ }^{1}$ Os textos citados são ainda inéditos, em tradução de Aline Larroyed.

Bibliografia

FERREIRA, Jerusa Pires. Armadilhas da Memória. São Paulo, Ateliê, 2004. 
SCHNAIDERMAN, Boris. Os Escombros e o Mito. São Paulo, Companhia das Letras, 1997.

SLAVUTZKY, Abrão (Org). A Paixão do Ser: depoimentos e ensaios sobre a identida de judaica. Artes Oficinas: Porto Alegre-RS, 1998.

STRUVE, Nikita. Óssip Mandelstam. Paris, Institut d’Études Slaves, 1982.

\section{Obras de Óssip Mandelstam:}

MANDELSTAM, Óssip. Eté Froid \& autres textes. Traduits du russe par Ghislaine Capogna-Bardet. Paris: Actes du Sud, 2004.

- (La) Pierre: les premières poésies (1906-1915). Traduit du russe et présenté par Henri Abril. Paris: Les Éditions Circe, 2003.

. Le Bruit du Temps. Traduit du russe et annoté par Edith Scherrer. Lausanne: Éditions L'Age d'Homme, 2001a.

- Poesia Russa Moderna. Trad. de Boris Schnaiderman, Augusto e Haroldo de Campos. 6a. ed. revista e ampliada. São Paulo, Perspectiva, 2001b.

. Lettres. Traduit du russe par Ghislaine Capogna-Bardet. Arles: Actes Sud, 2000a.

- O Rumor do Tempo e Viagem a Armênia. Tradução de Paulo Bezerra. São Paulo: Editora 34, 2000b.

. Tristia y otros poemas. Traducción, notas y epílogo de Jesús García Gabaldón. Málaga: Igitur, 1998.

. Le Sceau Égyptien. Traduit du russe par Claude B. Levenson. Lausanne: L’Age d'Homme, 1990a.

MANDELSTAM, Óssip. De la Poésie. Traduit du russe, présenté et annoté par Mayelasveta. Paris: Gallimard, $1990 \mathrm{~b}$.

. Voyage en Arménie. Traduction de André Bouchet. Paris: Mercure de France, 1984.

. Tristia et autres poèmes. Choisis et traduits du russe par François Kérel. Paris: Gallimard, 1982.

Poètes d'ajourd' bui. Paris: Seghers, 1972. 